\title{
The Inverted Phantom Giant
}

\author{
Matthias Erb
}

Published online: 17 May 2014

(C) Springer Science+Business Media New York 2014

In his famous children's book, "Jim Button and Luke the Engine Driver", Michael Ende describes a curious character: A phantom giant. Clothed in rags and with a long beard, the phantom giant appears enormous from far away, but shrinks to normal size as one gets closer. Most people avoid the poor creature, but the ones that dare approach it encounter a gentle, lonely being called Mr. Tur Tur. Chemical ecology is just the opposite of Mr. Tur Tur: A phantom dwarf. Or, in other words, an inverted phantom giant. From a distance, chemical ecology appears like a slightly odd, marginal section of biology and chemistry. But, as the interested scholar approaches, it starts growing and very quickly reaches gigantic dimensions, because all life is explained by chemistry, and all biological chemistry is guided by ecological principles. Herein lies the difficulty with chemical ecology: As it is not perceived well by biologists and chemists, few approach it to understand its significance, and the ones that do find themselves in front of a giant that defies their attempts to define and contain it. This is where the Journal of Chemical Ecology comes in: It invites us to take a closer look at an underestimated discipline and supports us to explore it and deal with its multidimensionality through the promotion of knowledge and methods. These services are unique and make the journal stand out of the crowd of scientific journals.
Writing children's books has become difficult in the era of information technology. And, so has the job of the Journal of Chemical Ecology. Young scientists gather information through accessible, dynamic websites and social platforms. They want articles that are available through a single mouse click, anywhere, anytime. They prefer advanced interactive hypertext protocols over clumsy pdf files. They care about transparency, non-profit and open access just as much as about traditional journal properties. In my view, reaching "the kids" is the major challenge of the Journal over the next years.

Promoting an inverted phantom giant in the $21^{\text {st }}$ century requires a combination of high-quality information and boosted visibility. In Michael Ende's book, Jim and Luke follow exactly this strategy with Mr. Tur Tur: They become friends and offer him a job as a living lighthouse to protect their small island. They combine a quality relationship with high visibility, et voilà, the story ends well! I am looking forward to seeing if the Journal of Chemical Ecology will follow a similar path to reach the next generation of biologists and chemists. If yes, there is a good chance that in 40 years from now, somebody will write a laudation and refer to another famous book by Michael Ende: "The Neverending Story".
M. $\operatorname{Erb}(\triangle)$

Institute of Plant Sciences, University of Bern, Bern, Switzerland

e-mail: matthias.erb@ips.unibe.ch 